ISSN: 2052-5206

journals.iucr.org/b

\title{
Structure and stability of $\mathrm{BaTiSi}_{2} \mathrm{O}_{7}$
}

\section{Alberto Viani, Andrea Palermo, Stefano Zanardi, Nicola Demitri, Václav Petrícek, Federico Varini, Elena Belluso, Kenny Ståhl and Alessandro Francesco Gualtieri}

Acta Cryst. (2015). B71, 153-163

\section{IUCr Journals CRYSTALLOGRAPHY JOURNALS ONLINE \\ Copyright (C) International Union of Crystallography \\ Author(s) of this paper may load this reprint on their own web site or institutional repository provided that this cover page is retained. Republication of this article or its storage in electronic databases other than as specified above is not permitted without prior permission in writing from the IUCr. \\ For further information see http://journals.iucr.org/services/authorrights.html}


STRUCTURAL SCIENCE CRYSTAL ENGINEERING MATERIALS

ISSN 2052-5206

Received 10 July 2014

Accepted 11 February 2015

Edited by Dr Th. Proffen, Oak Ridge National Laboratory, USA

Keywords: photo-luminescence; optical properties; solid-state reactions.

CCDC references: 1048900; 1048901

Supporting information: this article has supporting information at journals.iucr.org/b

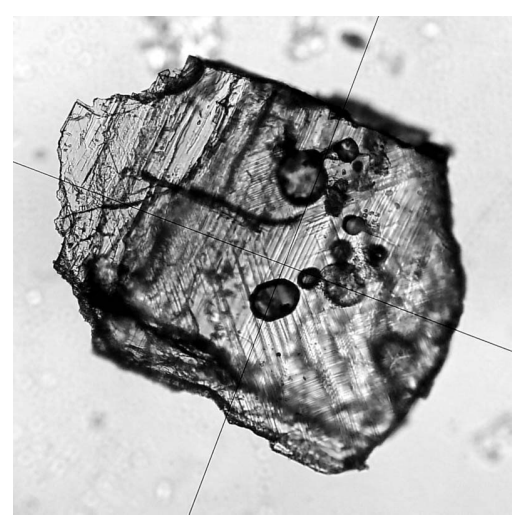

(C) 2015 International Union of Crystallography

\section{Structure and stability of $\mathrm{BaTiSi}_{2} \mathrm{O}_{7}$}

\author{
Alberto Viani, ${ }^{\mathrm{a} *}$ Andrea Palermo, ${ }^{\mathrm{b}}$ Stefano Zanardi, ${ }^{\mathrm{c}}$ Nicola Demitri, ${ }^{\mathrm{d}}$ Václav \\ Petrícek, ${ }^{\mathrm{e}}$ Federico Varini, ${ }^{\mathrm{b}}$ Elena Belluso, ${ }^{\mathrm{f}}$ Kenny Ståh ${ }^{\mathrm{g}}$ and Alessandro Francesco \\ Gualtieri $^{\mathrm{b}}$
}

\begin{abstract}
anstitute of Theoretical and Applied Mechanics ASCR, Centre of Excellence Telč, Batelovská 485, Telč CZ-58856, Czech Republic, ${ }^{\mathbf{b}}$ Università di Modena e Reggio Emilia, Dipartimento di Scienze Chimiche e Geologiche, Via S. Eufemia 19, Modena I-41121, Italy, ${ }^{\mathbf{C} E N I}$ s.p.a., Refining and Marketing Division, San Donato Milanese Research Center, Via F. Martiano 26, San Donato Milanese I-20097, Italy, 'dSincrotrone Trieste S.C.p.A., Strada Statale 14 - km 163,5, Basovizza I-34149, Italy, 'e Department of Physics, Academy of Sciences of the Czech Republic, Cukrovarnická 10, Praha 6, 162 53, Czech Republic, 'Dipartimento di Scienze della Terra, Università degli studi di Torino, Via Valperga Caluso 35, Torino I10125, Italy, and ${ }^{\mathrm{g}}$ Department of Chemistry, Technical University of Denmark, DTU:207, Lyngby DK-2800, Denmark. *Correspondence e-mail: viani@itam.cas.cz
\end{abstract}

Due to their optical, photo-luminescence (PL), and afterglow properties, barium titanosilicates are compounds of great interest for functional materials and lightemitting devices. Among them, $\mathrm{BaTiSi}_{2} \mathrm{O}_{7}$ (BTS2) is certainly one of the most intriguing; it displays peculiar properties (e.g. PL orange emission) whose exhaustive explanation has been hampered to date by the lack of a structure model. In this work, BTS2 and the related compound $\mathrm{BaTiSi}_{4} \mathrm{O}_{11}$ (BTS4) were synthesized through conventional solid-state reaction methods. BTS2 invariably shows complex twinning patterns. Thus, its structure solution and Rietveld structure refinement were attempted using synchrotron powder diffraction. BTS2 was found to be an intergrowth of monoclinic and triclinic crystals. The monoclinic phase has the space group $P 2_{1} / n$ and unit cell $a=7.9836$ (3), $b=$ 10.0084 (4), $c=7.4795$ (3) $\AA$, and $\beta=100.321(3)^{\circ}$, whereas the triclinic phase has the space group $P \overline{1}$ and unit cell $a=7.99385(4), b=10.01017(5), c=$ 7.47514 (3) ̊̊, $\alpha=90.084$ (8), $\beta=100.368$ (8) and $\gamma=89.937$ (9) ${ }^{\circ}$. These lattices can be seen as a distortion of that of tetragonal synthetic $\beta-\mathrm{BaVSi}_{2} \mathrm{O}_{7}$ with Ti in place of $\mathrm{V}$. The structure models obtained from this study confirm the presence of fivefold coordinated $\mathrm{Ti}$ atoms in a distorted pyramidal configuration. The proposed solution supports existing theories for the explanation of the PL orange colour in BTS2.

\section{Introduction}

The recent interest in barium titanosilicate compounds, specifically $\mathrm{Ba}_{2} \mathrm{TiSi}_{2} \mathrm{O}_{8}$ (mineral fresnoite), $\mathrm{BaTiSi}_{3} \mathrm{O}_{9}$ (BTS3, mineral benitoite) and $\mathrm{BaTiSi}_{2} \mathrm{O}_{7}$ (BTS2) as components for functional materials, arises mainly because of their photoluminescent (PL) properties. The relative availability of their constituting elements and absence of rare-earth dopants (unlike other PL synthetic compounds) was considered to justify these scientific efforts from both the environmental and economic point of view. The electronic configuration of the tetravalent $\mathrm{Ti}^{4+}$ ion has been recognized to be at the origin of the PL effect observed at room temperature in $\mathrm{Ti}^{4+}$-rich titanates (Gaft et al., 2004; Takahashi et al., 2006a). In BTS3, the intense blue PL is caused by an ultraviolet excitation, corresponding to the charge-transfer (CT) transition from the $2 p$ orbital of the surrounding oxygen ion to the empty outer $3 d$ orbital of $\mathrm{Ti}^{4+}$, in isolated octahedral $\mathrm{TiO}_{6}$ units (De Haart et al., 1985; Gaft et al., 2004). The CT mechanism cannot, however, explain the orange PL observed in BTS2 (Takahashi et al., 2008, 2012). Investigations of the physical properties of 
BTS2 have been performed in the absence of a structural model (Zhu et al., 2003; Takahashi et al., 2008, 2012). The PL effect in BTS2 was attributed to the presence of pyramidal $\mathrm{TiO}_{5}$ structural units facing in the opposite direction along the $c$ axis (Takahashi et al., 2006a). Such a configuration leads to intrinsic and extrinsic oxygen defects in the pyramidal unit pair. The presence of such clusters was conjectured assuming a partial isomorphism between the structure of BTS2 and the $\beta$ suzukiite mineral $\mathrm{BaVSi}_{2} \mathrm{O}_{7}$ (Liu \& Greedan, 1994; Stassen et al., 1998). Suzukiite occurs as two different polymorphs: $\beta$ suzukiite, the high-temperature one, whose structure was solved by Liu \& Greedan (1994), and $\alpha$-suzukiite, the lowtemperature one, indexed as orthorhombic by Matsubara et al. (1982) and supposed to have the haradaite $\left(\mathrm{SrVSi}_{2} \mathrm{O}_{7}\right)$ structure. The $\beta$ phase can be described as consisting of unbranched single $\left[\mathrm{Si}_{4} \mathrm{O}_{12}\right]^{8-}$ rings and $\left[\mathrm{VO}_{5}\right]^{6-}$ pyramids connecting rings in the $a b$ plane. They form layers linked by $\mathrm{Ba}$ ions stacked along the $c$ axis.

In BTS2, $\mathrm{Ti}-\mathrm{O}$ and $\mathrm{Si}-\mathrm{O}$ bond lengths, derived from IR and Raman spectroscopy, were found to be consistent with $\mathrm{Si}_{4} \mathrm{O}_{12}$ rings and $\mathrm{TiO}_{5}$ pyramidal units (Tarte, 1990; Stassen et al., 1998). The attempt at cell indexing from X-ray powder diffraction (XRPD) data (Stassen et al., 1998) suggested a monoclinic symmetry, with $a=11.8831$ (7), $b=10.0067$ (5), $c=$ 9.9156 (10) $\AA$ and $\beta=93.832(6)^{\circ}$. BTS2 structural solution from powders is a complicated task because of the great difficulty in obtaining the pure compound. Its limited stability field in the $\mathrm{BaO}-\mathrm{TiO}_{2}-\mathrm{SiO}_{2}$ system (Fig. 1, modified after Köppen \& Dietzel, 1976) invariably leads to the coexistence of $\mathrm{BaTiSi}_{4} \mathrm{O}_{11}$ (BTS4) and $\mathrm{BaTiSi}_{2} \mathrm{O}_{8}$, in addition to BTS2, as a result of the crystallization process (Köppen \& Dietzel, 1976). Furthermore, the structure of BTS4 is unknown and shows severe peak overlap with BTS2. A further critical aspect is the

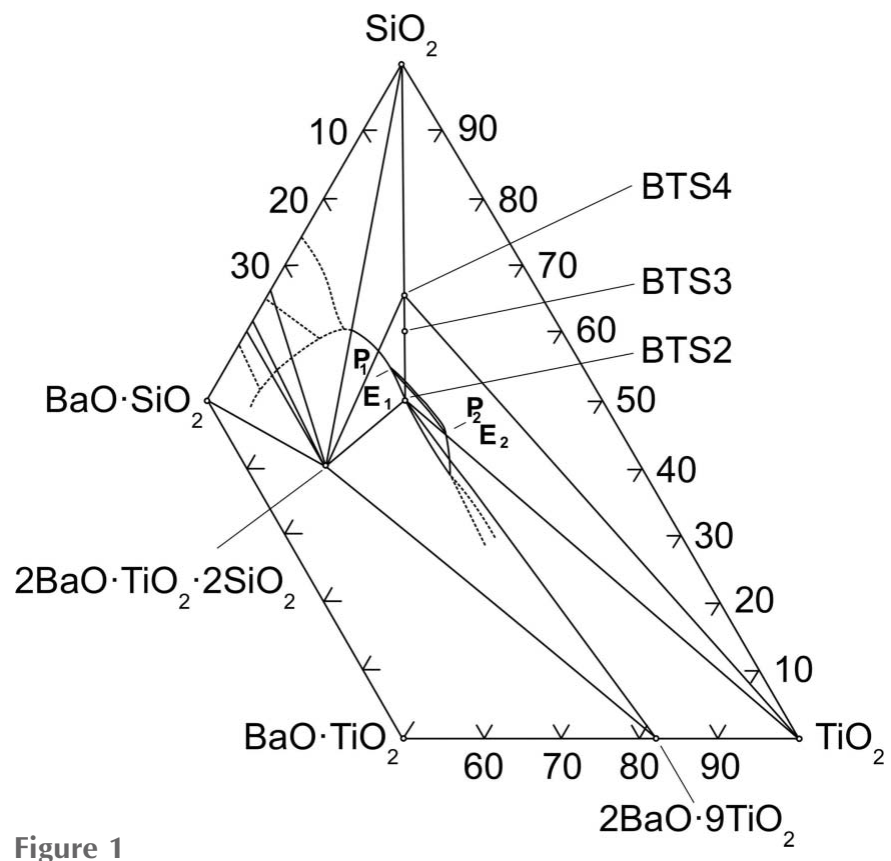

Portion of the $\mathrm{BaO}-\mathrm{TiO}_{2}-\mathrm{SiO}_{2}$ ternary phase diagram redrawn after Köppen \& Dietzel (1976). Data as mol\% of oxides. production of high-quality single crystals, invariably hindered by complex polysynthetic twinning occurring upon cooling at approximately 923-933 K (Köppen \& Dietzel, 1976). This work reports the solid-state synthesis of BTS2 and BTS4. On the obtained sample of BTS2, structure solution and XRPD Rietveld refinement were accomplished for the first time. Theories on PL properties of this compound in light of the structure model will be discussed.

\section{Experimental}

\subsection{Sample synthesis}

BTS2 and BTS4 were prepared through a conventional solid-state reaction method. Two different routes were followed. Synthesis A was designed to obtain the pure BTS2 phase and synthesis B to obtain the pure BTS4 phase. $\mathrm{Ba}(\mathrm{OH})_{2} \cdot 8 \mathrm{H}_{2} \mathrm{O}(99 \%), \mathrm{TiO}_{2}(99.7 \%)$ and $\mathrm{SiO}_{2}(99 \%)$ have been employed as sources of barium, titanium and silicon, respectively. Colloidal silica was employed in synthesis B in place of analytical grade $\mathrm{SiO}_{2}$.

Synthesis A. A mixture with molar composition $\mathrm{BaO}-\mathrm{TiO}_{2}-$ $2 \mathrm{SiO}_{2}$ was homogeneously mixed and wet ground in a porcelain mortar for $10 \mathrm{~min}$. The wet mixture was then dried at $393 \mathrm{~K}$.

Synthesis B. A mixture with molar composition $\mathrm{BaO}-\mathrm{TiO}_{2}-$ $4 \mathrm{SiO}_{2}$ was thoroughly mixed and dry ground in an agate shatterbox for $30 \mathrm{~min}$.

Each powder was pressed at 50 bars by means of a ceramic press. The obtained pellet, weighing $c a 30 \mathrm{~g}$, was placed in a platinum crucible for calcination. The thermal cycle was the same for both syntheses, and comprised a first heating step at $1373 \mathrm{~K}$ for $12 \mathrm{~h}$, and a second one at $1473 \mathrm{~K}$ for $12 \mathrm{~h}$. Both temperatures were achieved at the heating rate of $20 \mathrm{~K} \mathrm{~min}^{-1}$. After the second step the samples were allowed to cool down slowly to room temperature in about $24 \mathrm{~h}$. The optical inspection of the product of synthesis A showed at least two different crystal families. Part of the obtained tablet was therefore gently crushed and the material sieved at 500 and $200 \mu \mathrm{m}$. BTS 2 crystals were manually selected from the middle and fine residuals, under the optical microscope $(2 \times / 4 \times)$, in reflected light mode. Further aspects, such as mosaic texture, cleavage, fracturing, twinning and inclusions, were investigated under the petrographic microscope in planeand crossed-polarized light. A fraction of the selected crystals was finely ground in an agate mortar for XRPD analysis. Selected homogeneous products obtained from synthesis B were finely ground in an agate mortar for XRPD analysis.

\subsection{Analytical methods}

2.2.1. Scanning electron microscopy (SEM) and energy dispersive spectroscopy (EDS) analysis. Crystals selected under the optical microscope were studied with SEM and EDS analysis to inspect the surface morphology and determine a semi-quantitative chemical analysis. Fragments of the crystals were placed on an aluminium slab and coated with an Au thin layer of $10 \mathrm{~nm}$. The instrument used was a Philips XL-30 
working with a maximum beam voltage of $25 \mathrm{kV}$. Both secondary and back-scattered electron images were collected and interpreted with the aid of spot EDS analysis.

2.2.2. Electron microprobe analysis (EPMA) with wavelength dispersive spectroscopy (WDS). The instrument used was a Jeol 8200 super probe working with a maximum beam voltage of $30 \mathrm{kV}$. Images collected with back-scattered electrons were used as a basis for the spot WDS analysis. At least a five-point analysis was collected for each crystal.

2.2.3. Transmission electron microscopy (TEM). Selected crystals from synthesis A were also observed with TEM using the selected-area electron diffraction (SAED) mode. For the specimen preparation, the crystals were gently pulverized and dispersed in distilled water. Drops of the suspension were placed on a copper grid to dry. The instrument used was a Jeol JEM 2010 with a maximum beam voltage of $200 \mathrm{kV}$.

2.2.4. Laboratory XRPD. Qualitative XRPD data were collected on the synthesis product using a $\theta / \theta$ diffractometer, PANalytical X'Pert Pro (NL), equipped with a fast RTMS detector, and $\mathrm{Cu} K \alpha$ radiation ( $40 \mathrm{kV}$ and $40 \mathrm{~mA}$ ). A zerobackground silicon sample holder was used for all the measurements. The following instrumental conditions were used: $20-80^{\circ} 2 \theta$ range, a virtual step scan of $0.0167^{\circ} 2 \theta$ and virtual time per step of $50 \mathrm{~s}, 0.125^{\circ}$ divergence slit, $0.125^{\circ}$ antiscattering slit, $0.04 \mathrm{rad}$ soller slits, and a $10 \mathrm{~mm}$ copper mask mounted in the incident beam pathway. The pathway of the diffracted beam included an Ni filter, soller slits (0.04 rad) and an anti-scatter blade $(5 \mathrm{~mm})$.

2.2.5. Synchrotron XRPD. XRPD data suitable for structure determination and refinement were also collected at room temperature for BTS2 at two different synchrotron facilities:

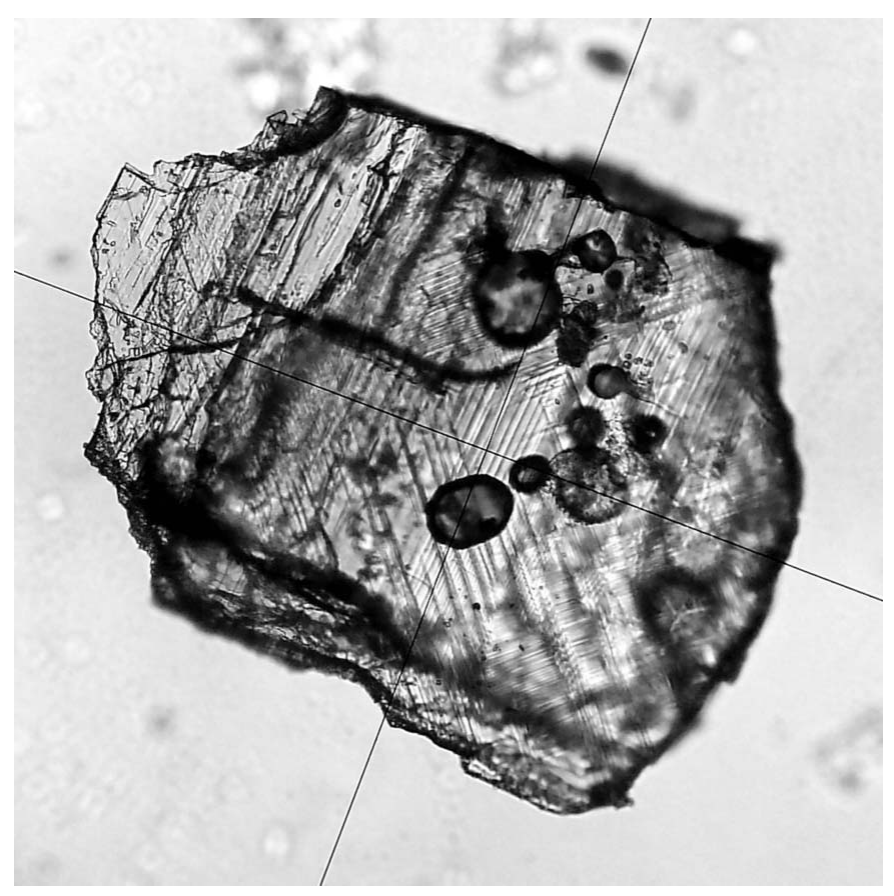

Figure 2

Example of BTS2, approximately $250 \mu \mathrm{m}$ in size, under the optical microscope. (i) Set-up 1, beamline XRD1 at Elettra (Trieste, Italy). Three different sample powders were placed in a quartz capillary with a diameter of $0.3 \mathrm{~mm}$ for the data measurements. The capillary was allowed to spin during the data collection. The experimental wavelength was set at $0.7 \AA$ and calibrated at the selenium absorption edge. Further fine calibration was obtained using silicon NITS $640 \mathrm{~b}$ as the calibrant substance in FIT2D software (Hammersley, 1993). A Pilatus $2 \mathrm{M}$ detector was placed $89 \mathrm{~mm}$ from the capillary. Six different single shots with exposure times of 50-100 s were taken. All the two-dimensional diffraction raw data were processed using the FIT2D software to obtain $2 \theta$ intensity patterns with an increment of $0.044^{\circ} 2 \theta$.

(ii) Set-up 2, high-resolution powder diffraction beamline ID31 (now ID22) at ESRF (Grenoble, France). A sample powder was placed in a glass capillary with a diameter of $0.3 \mathrm{~mm}$ for the data measurements and the capillary was allowed to spin during the data collection. The wavelength of the experiment was set at $0.3998 \AA$ and calibrated using standard NIST 660a $\mathrm{LaB}_{6}$. Diffracted intensities were vertically scanned by a bank of nine detectors (multianalyser stage) preceded by a $\mathrm{Si}(111)$ analyser crystal. The data reduction was performed with an increment of $0.00075^{\circ} 2 \theta$.

2.2.6. Synchrotron single-crystal diffraction. Structure solution of BTS2 from single-crystal data was attempted employing the experimental set-up 1 described above. Several single crystals with size between 30 and $50 \mu \mathrm{m}$, showing sharp extinction under the microscope, were tested. The size of the beam was $100 \times 100 \mu \mathrm{m}$, after preliminary tests, data were collected at the sample-to-detector distance of $90 \mathrm{~mm}$, with an exposure time of $10 \mathrm{~s}$ for each frame. For each data set, 120 images were collected by rotating the crystal $180^{\circ}$. Data were reduced and analysed using the iMosflm 1.0.7 software (http:// www.mrc-lmb.cam.ac.uk/harry/imosflm/ver710/).

2.2.7. Indexing, solution and structure refinement. Indexing of the BTS2 powder patterns was attempted using the TREOR program (Werner et al., 1985) implemented in WinPlotr for Windows (http://www-llb.cea.fr/fullweb/ powder.htm). CHEKCELL software (Laugier \& Bochu, 2014) was also used to cross-check the results. The structure solution of BTS2 was possible using the EXPO2013 software (Altomare et al., 2009, 2013). The Rietveld structure refinements were performed using the GSAS software package (Larson \& Von Dreele, 2004) with its graphical interface EXPGUI (Toby, 2001). The starting structural model obtained from EXPO2013 was used for the refinement of the structure. The peak profile was modelled using a multi-term Simpson's rule integration of the pseudo-Voigt function as implemented in $G S A S$ with one Gaussian and two Lorentzian (isotropic size and strain broadening) profile terms as well as peak asymmetry. The background was fitted with a shifted Chebyshev function (with variable number of terms depending on its complexity). Scale factors and the zero shift were always refined. Formal atomic charges were used for all the atomic species. Soft constraints with a starting weight $F$ of 1000000 were imposed in the initial steps of the refinement, and later progressively decreased to 25 . Bond-valence calculations for 
structure validation were carried out using VaList (https:// dl.dropboxusercontent.com/u/8933134/Website/Site/Software/ Software.html).

\section{Results}

Fig. 2 shows BTS2 crystals with a tabular crystal habit, beautiful twinning patterns and inclusions. The crystals are invariably sitting on the (100) pinacoidal face. This assumption was later confirmed by the presence of strong preferred orientation effects displayed by the (011) and (022) crystal faces in the powder patterns collected in the reflection mode. Polysynthetic twinning has already been reported for BTS2 (Köppen \& Dietzel, 1976). Twins are parallel to the (100) plane and resemble those observed for other monoclinic phases such as larnite $\beta-\mathrm{Ca}_{2} \mathrm{SiO}_{4}$ (Deer et al., 2013) and synthetic $\beta-\mathrm{Sr}_{2} \mathrm{SiO}_{4}$ (Catti et al., 1983), both refined in the $P 2_{1} / n$ space group. As a matter of fact, polysynthetic (100) twinning is always present in these low-temperature monoclinic forms, representative of twin-lattice-quasisymmetry twinning, where the lattices of the two orientations are slightly

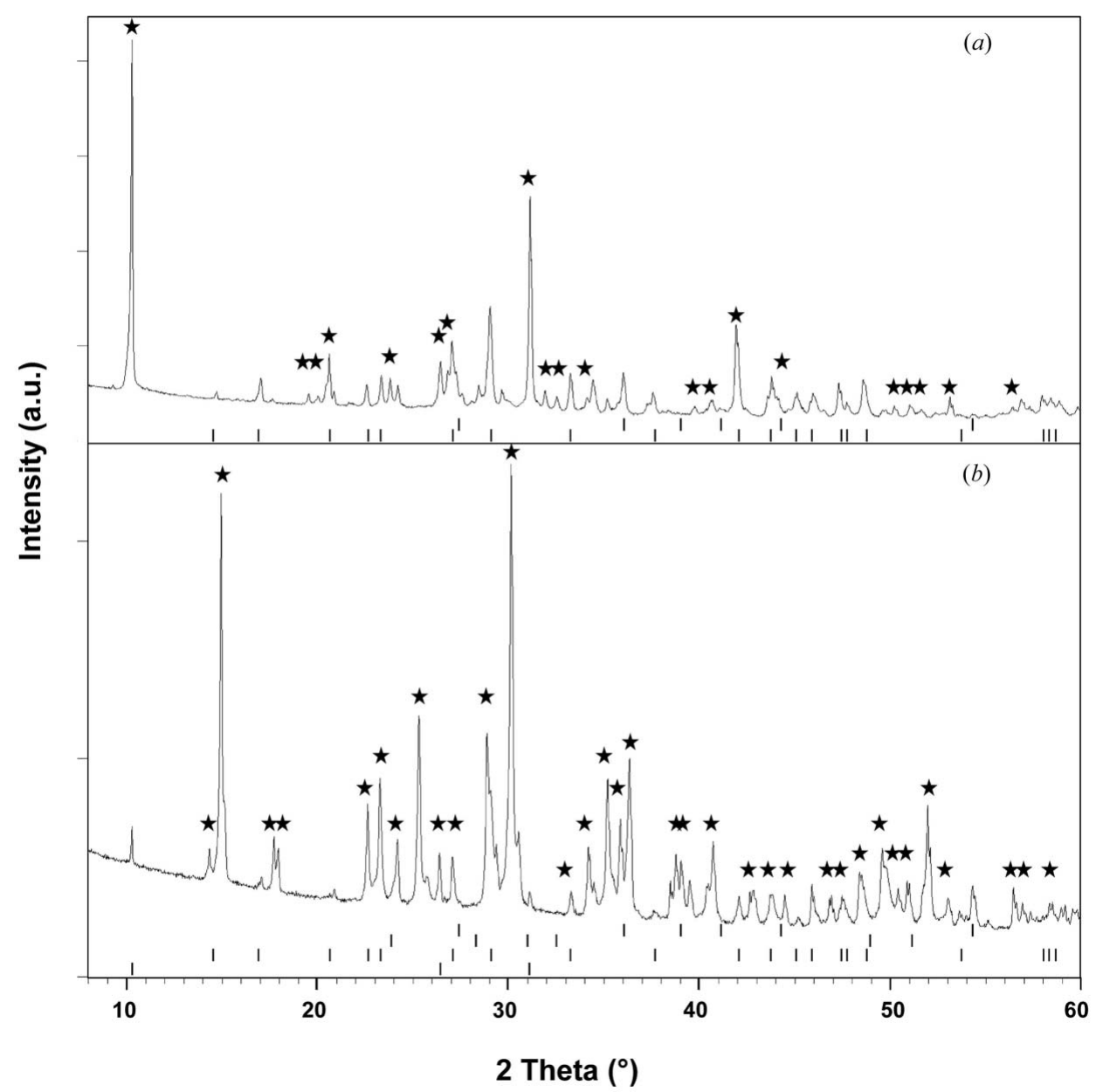

Figure 3

Powder diffraction patterns of the products of synthesis from laboratory data. Stars mark main Bragg reflection positions of BTS4 in $(a)$ and BTS2 in $(b)$. Markers at the bottom of each diffraction pattern indicate selected Bragg reflection positions of additional phases. In (a) (from the top): rutile, fresnoite; in (b): rutile, BTS3, fresnoite, BTS4. rotated, with obliquity angle depending on the $\beta$ angle (Donnay \& Donnay, 1974). In general, such twinning is referred to as pseudo-merohedry and occurs in monoclinic structures with the $\beta$ angle close to $90^{\circ}$ (Parsons, 2003). Crystals twin during cooling as they transform from a hightemperature phase of higher symmetry to a low symmetry (monoclinic and/or triclinic) modification and this transition is regarded as solid-state transformation twinning (Žák, 1973).

Fig. 3 reports the powder patterns collected of the synthesis products of BTS2 and BTS4 in reflection mode. The main features of the powder pattern of BTS2 (synthesis A) are the strong reflections at 5.93 and $2.96 \AA$ (14.95 and $30.12^{\circ} 2 \theta$ in Fig. 3, respectively) and a number of other intense reflections: at $3.52\left(25.28^{\circ} 2 \theta\right), 3.09\left(28.26^{\circ} 2 \theta\right), 2.55\left(35.19^{\circ} 2 \theta\right), 2.47$ $\left(36.34^{\circ} 2 \theta\right)$ and $1.76 \AA\left(51.95^{\circ} 2 \theta\right)$. The intensities of the former couple of reflections were found to be dependent on sample preparation, because, as will be shown later, they correspond to the above-mentioned (011) and (022) reflections displaying preferred orientation. BTS2 is accompanied by some other phases too. Rutile, BTS4, BTS3 and fresnoite have been identified. The two most intense peaks of BTS4, occurring at $8.60 \AA\left(10.28^{\circ} 2 \theta\right)$ and $2.87 \AA\left(31.12^{\circ} 2 \theta\right)$, can be easily recognized in Fig. 3( $a)$. The powder diffraction pattern of BTS4 (synthesis B) is characterized by a number of strong reflections occurring at $8.60\left(10.28^{\circ} 2 \theta\right), 2.87$ $\left(31.12^{\circ} 2 \theta\right), 2.15\left(41.91^{\circ} 2 \theta\right), 1.723$ $\left(53.11^{\circ} 2 \theta\right)$ and $1.435 \AA\left(64.89^{\circ} 2 \theta\right)$ (see Table $\mathrm{S} 1$ of the supporting information for the full list of reflections). It should be noted that the latter four $d$-spacing values are in the ratios 1:3, 1:4, 1:5 and 1:6 with the first one, suggesting diffraction from families of parallel crystallographic planes. As will be shown later, the shape of BTS4 crystals is compatible with some degree of preferred orientation; thus it is likely for these intensities to be affected by preferred orientation. In this sample fresnoite was also detected. Some of its main peaks can be easily recognized on the BTS4 diffraction pattern.

Fig. 4 depicts the back-scattered electron image of a BTS2 heterogeneous crystal, showing characteristic twinning and some small inclusions of fresnoite and $\mathrm{Ba}-\mathrm{Ti}$ oxides. Points of WDS spot analyses for BTS2 crystals (S5, S6, S7, S8), fresnoite (S9) and oxides inclusions (S10, S11) are indicated. The chemical composition of the 
Table 1

Results of the structure refinement of BTS2.

For all structures: $Z=4$. Experiments were carried out at $295 \mathrm{~K}$ with synchrotron radiation, $\lambda=0.70448 \AA$.

\begin{tabular}{|c|c|c|}
\hline & Set-up 1 & Set-up 2 \\
\hline \multicolumn{3}{|l|}{ Crystal data } \\
\hline Chemical formula & $\mathrm{BaTiSi}_{2} \mathrm{O}_{7}$ & $\mathrm{BaTiSi}_{2} \mathrm{O}_{7}$ \\
\hline$M_{\mathrm{r}}$ & 350.88 & 353.39 \\
\hline Crystal system, space group & Monclinic, $P 2_{1} / n$ & Triclinic, $P \overline{1}$ \\
\hline$a, b, c(\AA)$ & $7.9836(3), 10.0084(4), 7.4795(3)$ & $\begin{array}{l}7.99385(4), 10.01017(5), \\
\quad 7.47514(3)\end{array}$ \\
\hline$\alpha, \beta, \gamma\left({ }^{\circ}\right)$ & $90,100.321(3), 90$ & $90.084(8), 100.368(8), 89.937(9)$ \\
\hline$V\left(\AA^{3}\right)$ & $587.97(5)$ & $588.39(1)$ \\
\hline Specimen shape & Powder & Powder \\
\hline \multicolumn{3}{|l|}{ Data collection } \\
\hline Diffractometer & Four-circle Huber & $\begin{array}{l}\text { Goniometer especially built by } \\
\text { Rotary Precision Instruments } \\
\text { (UK) }\end{array}$ \\
\hline Specimen mounting & Glass capillary, $0.3 \mathrm{~mm}$ diameter & Glass capillary, $0.3 \mathrm{~mm}$ diameter \\
\hline Data collection mode & Transmission & Transmission \\
\hline Scan method & $\begin{array}{l}\text { Five single shots of } 50-100 \mathrm{~s} \\
\text { collected on a } 2 \mathrm{D} \text { PILATUS } \\
\text { detector at fixed wavelength of } \\
0.7 \AA\end{array}$ & $\begin{array}{l}\text { Angle dispersive at fixed wave- } \\
\text { length of } 0.3998 \AA\end{array}$ \\
\hline $2 \theta$ values $\left({ }^{\circ}\right)$ & $\begin{array}{l}2 \theta_{\min }=0.011,2 \theta_{\max }=65.412 \\
2 \theta_{\text {step }}=0.044\end{array}$ & $\begin{array}{l}2 \theta_{\min }=0.505,{ }_{\text {max }}=38.0012 \theta_{\text {step }}= \\
\quad 0.002\end{array}$ \\
\hline \multicolumn{3}{|l|}{ Refinement } \\
\hline \multirow[t]{2}{*}{$\begin{array}{l}R \text { factors and goodness of fit } \\
(\%) \dagger\end{array}$} & $\begin{array}{l}R_{\mathrm{p}}=0.042, R_{\mathrm{wp}}=0.054, R_{\exp }= \\
\quad 0.006, R\left(F^{2}\right)=0.09784, \chi^{2}= \\
\quad 13.08\end{array}$ & $\begin{array}{l}R_{\mathrm{p}}=0.082, R_{\mathrm{wp}}=0.107, R_{\mathrm{exp}}= \\
0.028, R\left(F^{2}\right)=0.08716, \chi^{2}= \\
14.90\end{array}$ \\
\hline & $\begin{array}{l}R_{\mathrm{p}, \text { bck sub }}=0.042, R_{\mathrm{wp}, \text { bck sub }}= \\
0.051\end{array}$ & $\begin{array}{l}R_{\mathrm{p}, \mathrm{bck} \text { sub }}=0.097, R_{\mathrm{wp}, \mathrm{bck} \text { sub }}= \\
0.130\end{array}$ \\
\hline No. of data points & 1474 & 18749 \\
\hline No. of parameters & 179 & 109 \\
\hline No. of restraints & 8 & 16 \\
\hline$(\Delta / \sigma)_{\max }$ & 0.04 & 0.17 \\
\hline
\end{tabular}

$\dagger R_{\mathrm{p}}, R_{\mathrm{wp}}, R_{\mathrm{wp}, \text { bck sub}}, R_{\mathrm{p} \text {, bck sub }}$ and $\chi^{2}$, as defined in GSAS (Larson \& Von Dreele, 2004).
$\mathrm{Ba}_{0.93} \mathrm{Ti}_{1.01} \mathrm{Si}_{2.02} \mathrm{O}_{7}$ (Table S2). Ba-Ti oxide inclusions showed a $\mathrm{BaO}: \mathrm{TiO}_{2}$ ratio of 1:3. The estimated uncertainty of the measure is $0.001 \mathrm{wt} \% .12$ spot analyses were also collected on BTS4 crystals and the resulting chemical formula, calculated assuming 11 oxygen a.p.f.u., was $\mathrm{Ba}_{1.02} \mathrm{Ti}_{0.9} \mathrm{Si}_{4.1} \mathrm{O}_{11}$. The results of the structure solution/ refinements revealed that the average structure is monoclinic and the lowresolution synchrotron XRPD data (Set-up 1) are well fitted using this model. However, careful inspection of the high-resolution synchrotron XRPD pattern (Set-up 2) showed some peak splitting, suggesting a lower symmetry, compatible with a triclinic $P \overline{1}$ model. Use of the triclinic model alone was found to be insufficient to fit the data and only a combination of both the triclinic and the monoclinic models resulted in a satisfactory fit.

Table 1 reports the results of the structure refinement of BTS2 in the monoclinic space group $P 2_{1} / n$ using low-resolution synchrotron XRPD data. An example of the corresponding graphical outputs of the structure refinement is reported in Fig. 5(a). The results of the structure refinement of BTS2 in the triclinic

BTS2 crystals was calculated assuming seven $\mathrm{O}$ atoms per formula unit (a.p.f.u.). The mean formula obtained was space group $P \overline{1}$ using the high-resolution synchrotron XRPD data collected with Set-up 2 are also reported in Table 1. The
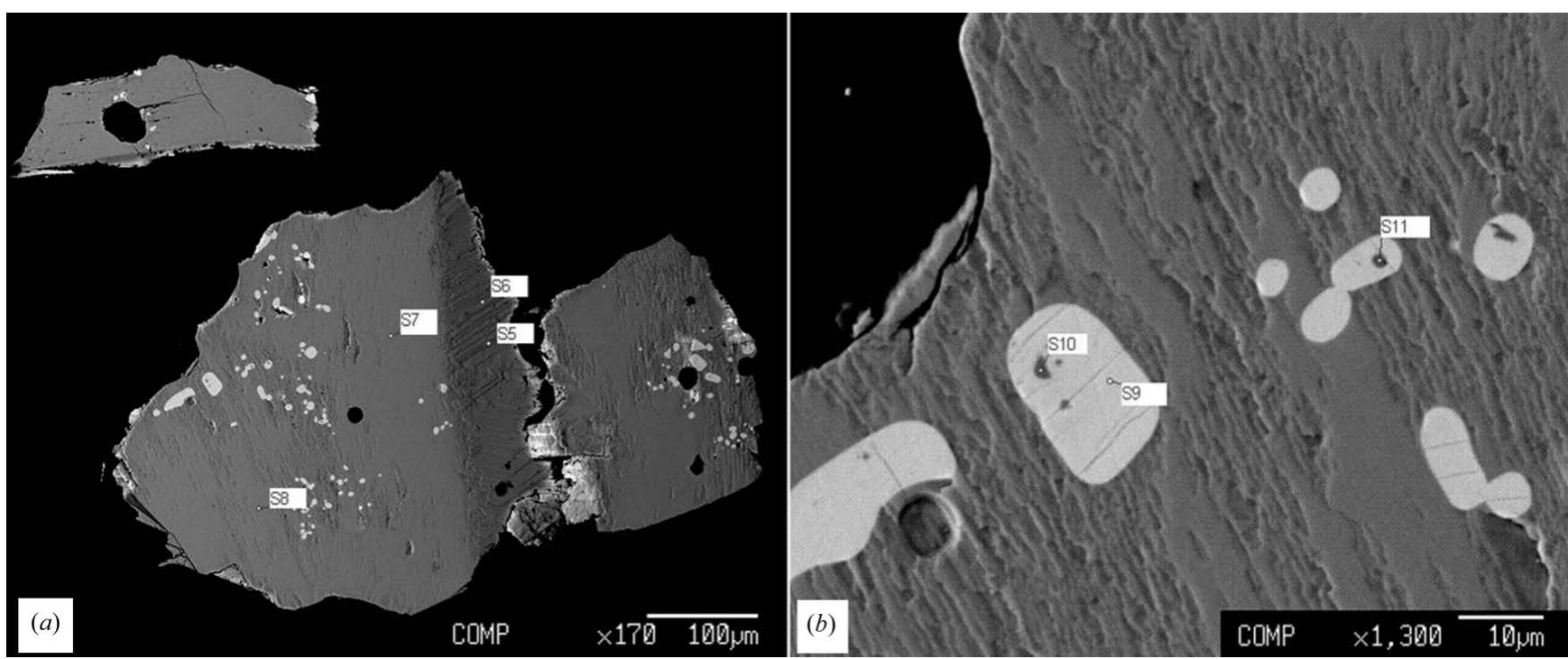

Figure 4

Back-scattered electron image of a BTS2 heterogeneous crystal $(a)$. Inclusions of fresnoite and Ba-Ti oxides are light grey. In $(b)$ the inclusions are at a higher magnification. Labels indicate locations of WDS spot analysis. 
effect of the different resolution is highlighted in Figs. 5(b) and (c), where XRPD data in a selected $d$-spacing range were compared. The final model determined using data collected with Set-up 2 is thus a mixture of monoclinic [40.2 (3) wt \%] and triclinic phases [58.9 (2) wt \%] with very minor impurities of frenosite $[0.8(4) \mathrm{wt} \%]$ and benitoite [0.1 (1) wt \%].
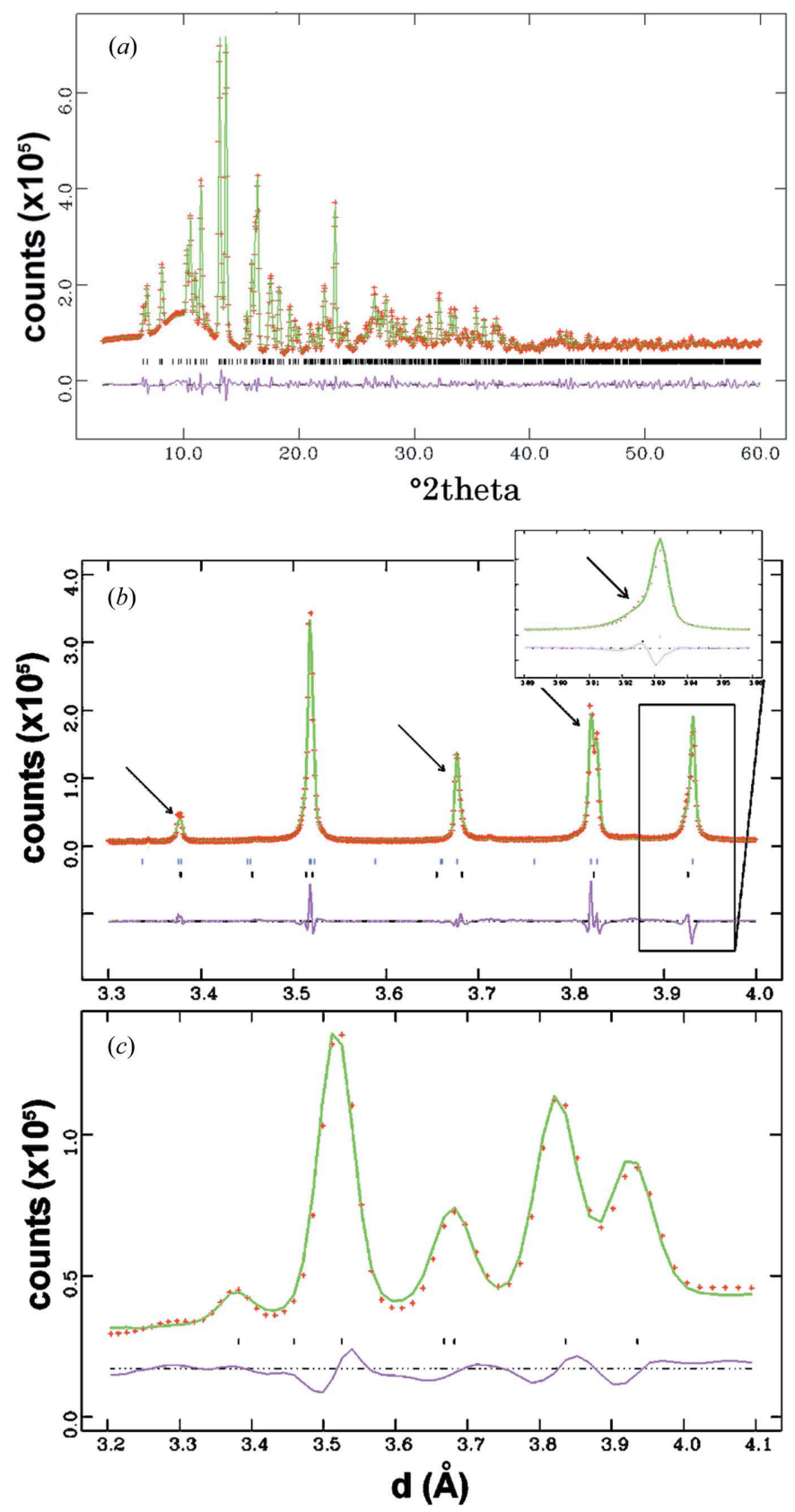

Figure 5

Examples of graphical outputs of the structure refinement with the observed, calculated and difference curve. (a) Fit using one of the six data sets collected at the synchrotron facility (Set-up 1). Markers of each reflection are also plotted; $(b)$ fit in a selected $d$-spacing range using the high-resolution data (Set-up 2). Peak splitting is indicated by black arrows. The lower marker line refers to the monoclinic structure and the upper marker line refers to the triclinic structure; $(c)$ the same $d$-spacing range using the data collected in with Set-up 1 with no evidence of peak splitting due to the large peak widths.
Table 2

Selected interatomic distances (A) calculated from the structure refinement of monoclinic BTS2.

\begin{tabular}{ll}
\hline $\mathrm{Ti}-\mathrm{O} 1$ & $2.13(3)$ \\
$\mathrm{Ti}-\mathrm{O} 2$ & $2.00(2)$ \\
$\mathrm{Ti}-\mathrm{O} 4$ & $1.641(6)$ \\
$\mathrm{Ti}-\mathrm{O} 6$ & $1.93(1)$ \\
$\mathrm{Ti}-\mathrm{O} 7$ & $1.94(1)$ \\
$\mathrm{Ba}-\mathrm{O} \dagger$ & $3.085(3)$ \\
\hline
\end{tabular}

$\dagger$ Mean value over 12 distances.

Refinement of the triclinic structure was only possible by constraining the structure of the monoclinic one.

A reliable and robust final structure model for triclinic BTS2 was made possible only thanks to the very high quality of the high-resolution synchrotron XRPD data, although this may be considered a limiting case for the Rietveld refinement, given the close coexistence of two similar polymorphs. It should be emphasized that the right choice of experimental conditions is crucial in view of the structure solution from XRPD. Sometimes, structural complexity can only be described by last generation high-resolution instruments, even when synchrotron radiation is employed, because subtle diffraction features may be masked by instrumental broadening and aberrations. Table 2 reports selected calculated interatomic distances for the monoclinic BTS2 structure, using data from Set-up 1. Complete crystallographic information for both structures is reported in the CIF file of the supporting information.

Table 3 reports the results of the bond-valence calculations using the VaList program for both the monoclinic and triclinic models. Deviations from the assumed states are lower than $9 \%$ for the monoclinic structure and lower than $6 \%$ for the triclinic structure. Calculations were accomplished assuming full occupancy of the crystallographic sites. The first refinement of the monoclinic structure showed unusually high atomic displacement parameters for $\mathrm{O} 1$ compared with neighbouring $\mathrm{O}$ atoms. This was also accompanied by the undersaturation of the corresponding site, as reported in Table 3. The application of an absorption correction (DebyeScherrer model for capillary) and selective exclusion from the refinement of single datasets in turn did not improve the final result. Although the values of atomic displacement parameters may be affected by several correlations in such a complex structural refinement, an attempt was made to refine the site occupancy of $\mathrm{O} 1$ by fixing the atomic displacement parameter to a value close to those of the neighbouring $\mathrm{O}$ atoms, and after convergence to refine the atomic displacement parameter fixing the population. The strong correlation of atomic displacement parameters and site occupancy prevented their simultaneous refinement. The atomic displacement parameter refined at an acceptable value (see CIF in the supporting information) and the population of the $\mathrm{O} 1$ resulted in 0.84. Fig. 6 reports one TEM SAED pattern along the [100] axis of the BTS2 phase showing the $b$ and $c$ axes $(a)$ and the relative simulation $(b)$. It was not possible to detect crystals oriented in directions other than (100). Fig. 7 depicts 
crystal species and habits present in the reaction products from synthesis A, under SEM. The corresponding simulation of the crystal habit, calculated using the Krystalshaper software (http://www.jcrystal.com/products/krystalshaper) is also shown. Figs. 8(a) and $(b)$ show the calculated structure model of monoclinic BTS2 in the $a b$ and $a c$ planes, respectively. The triclinic structure being a lattice distortion of the monoclinic one, very slight differences can be seen by a graphical comparison of the two models (an example of the triclinic structure is shown in Fig. S1 of the supporting information). Despite our efforts in the optimization of the experimental conditions and careful selection of individuals for singlecrystal diffraction experiments, diffraction spots resulted which were split or streaked (Fig. S2). This indicates that even very small sub-micrometric crystals are twinned and/or present the coexistence of the triclinic and monoclinic phases. Owing to such a complex crystal assemblage, indexing of the single-crystal data sets, the first step towards the structure solution, invariably failed.

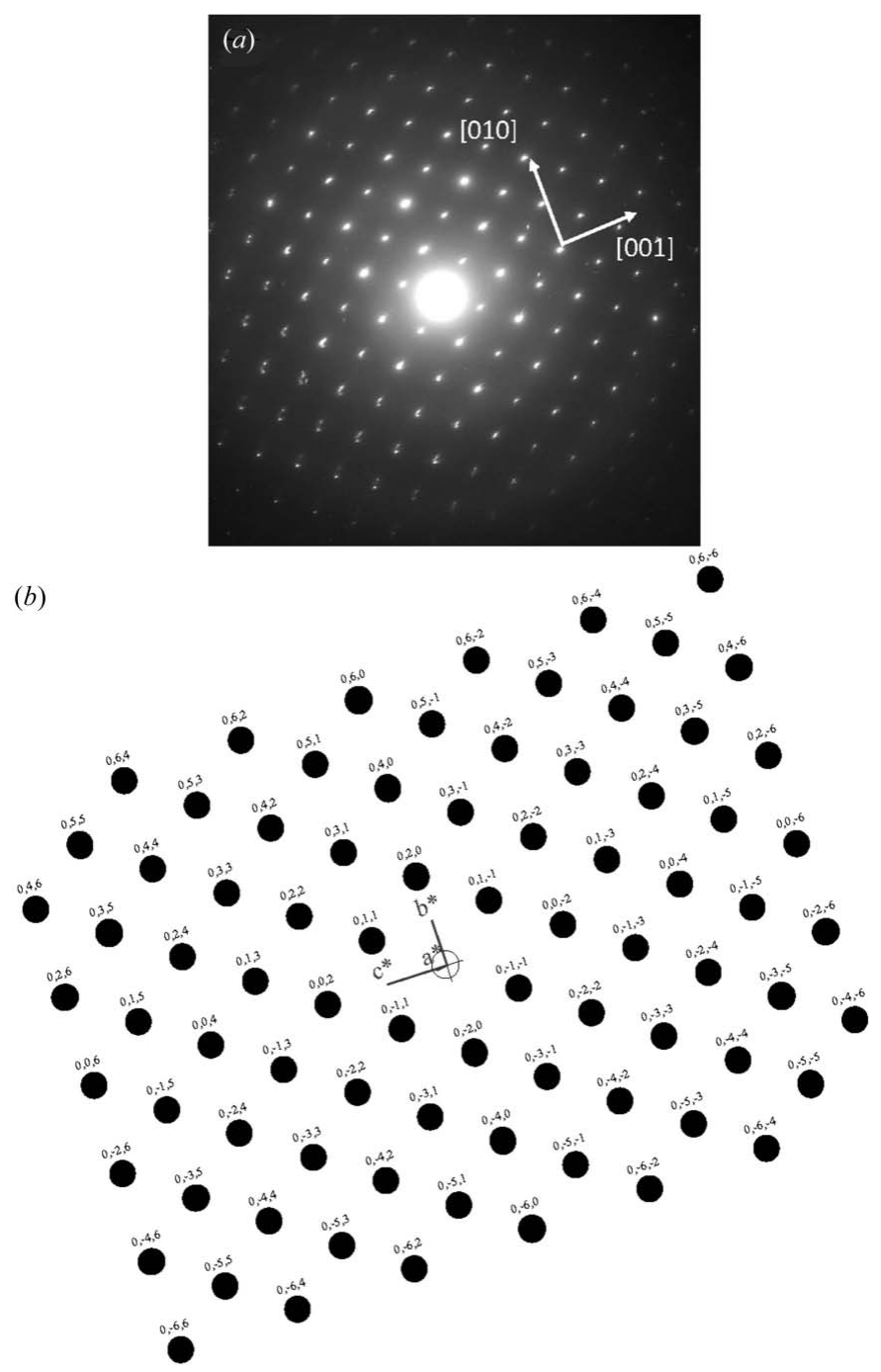

Figure 6

Example of TEM SAED picture of BTS2 along the monoclinic [100] axis, with the orthogonal $b$ and $c$ axes $(a)$ and the relative simulation $(b)$.
Table 3

Bond-valence balance calculation from the structure refinement of monoclinic BTS2 and triclinic BTS2.

\begin{tabular}{|c|c|c|c|c|c|}
\hline \multicolumn{3}{|c|}{ Monoclinic (Set-up 1) } & \multicolumn{3}{|c|}{ Triclinic (Set-up 2) } \\
\hline Atom & $\begin{array}{l}\text { Bond- } \\
\text { valence } \\
\text { sum }\end{array}$ & $\begin{array}{l}\text { \% deviation } \\
\text { from assumed } \\
\text { state }\end{array}$ & Atom & $\begin{array}{l}\text { Bond- } \\
\text { valence } \\
\text { sum }\end{array}$ & $\begin{array}{l}\% \text { deviation } \\
\text { from assumed } \\
\text { state }\end{array}$ \\
\hline \multirow[t]{2}{*}{ Ba1 } & 2.000 & 0 & Ba1 & 2.061 & 3 \\
\hline & & & $\mathrm{Ba} 2$ & 2.101 & 5 \\
\hline \multirow[t]{2}{*}{ Ti1 } & 4.007 & 0 & Ti1 & 4.103 & 3 \\
\hline & & & $\mathrm{Ti} 2$ & 4.109 & 0 \\
\hline \multirow[t]{2}{*}{ Si1 } & 3.729 & 7 & Si1 & 3.971 & 1 \\
\hline & & & $\mathrm{Si} 2$ & 3.898 & 3 \\
\hline \multirow[t]{2}{*}{$\mathrm{Si} 2$} & 4.050 & 1 & $\mathrm{Si} 3$ & 4.003 & 0 \\
\hline & & & $\mathrm{Si} 4$ & 3.999 & 0 \\
\hline \multirow[t]{2}{*}{ O1 } & 1.858 & 7 & $\mathrm{O} 1$ & 1.880 & 6 \\
\hline & & & $\mathrm{O} 2$ & 2.035 & 2 \\
\hline \multirow[t]{2}{*}{$\mathrm{O} 2$} & 2.186 & 9 & $\mathrm{O} 3$ & 2.047 & 2 \\
\hline & & & $\mathrm{O} 4$ & 2.065 & 3 \\
\hline \multirow[t]{2}{*}{$\mathrm{O} 3$} & 2.052 & 3 & O5 & 2.033 & 2 \\
\hline & & & O6 & 2.110 & 5 \\
\hline \multirow[t]{2}{*}{$\mathrm{O} 4$} & 1.926 & 4 & $\mathrm{O} 7$ & 1.908 & 5 \\
\hline & & & O8 & 2.056 & 3 \\
\hline \multirow[t]{2}{*}{$\mathrm{O} 5$} & 1.941 & 3 & O9 & 2.086 & 4 \\
\hline & & & O10 & 2.215 & 6 \\
\hline \multirow[t]{2}{*}{ O6 } & 2.010 & 0 & O11 & 1.911 & 4 \\
\hline & & & O12 & 2.015 & 1 \\
\hline \multirow[t]{2}{*}{$\mathrm{O} 7$} & 1.813 & 9 & O13 & 1.881 & 6 \\
\hline & & & O14 & 2.003 & 0 \\
\hline
\end{tabular}

Assumed valence state for $\mathrm{Ba}=+2, \mathrm{Ti}=+4, \mathrm{Si}=+4, \mathrm{O}=-2$.

\section{Discussion}

The primary stability fields of BTS2 and BTS4 were described as two very thin, roughly parallel stripes in the $\mathrm{BaO}-\mathrm{TiO}_{2}-$ $\mathrm{SiO}_{2}$ ternary diagram (Köppen \& Dietzel, 1976; see Fig. 1). The stability field of BTS2 is comprised within the range 22$26 \mathrm{~mol} \% \mathrm{BaO}$, with the point of exact stoichiometry lying within the fresnoite stability field. The primary field of BTS4 is confined to between that of $\mathrm{SiO}_{2}$ and BTS2. The four peritectic and eutectic points $\mathrm{P} 1-\mathrm{P} 2$ and E1-E2 define a very small
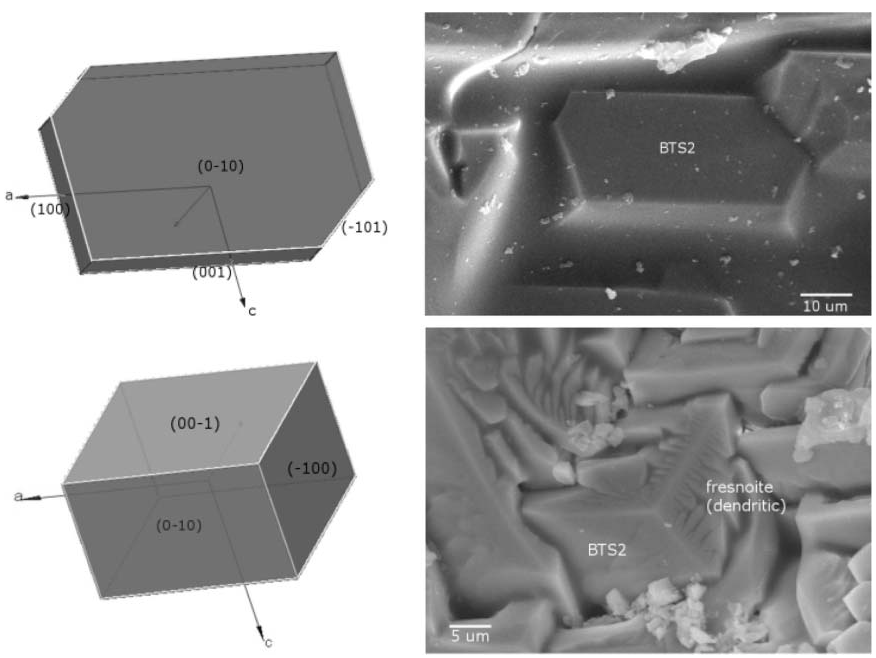

Figure 7

SEM images of BTS2 synthetic crystals with their relative morphological simulation of a monocline symmetry crystal. 
area on the plot in Fig. 1; the points P1-E1 and P2-E2 are so close together that they cannot be rendered at the scale of the drawing. Crystallization experiments in the range of compositions close to $\mathrm{BaO}-\mathrm{TiO}_{2}-2 \mathrm{SiO}_{2}$ showed the difficulties in obtaining the pure BTS2 phase (Köppen \& Dietzel, 1976), with BTS4 and fresnoite being frequently detected. An increase in $\mathrm{SiO}_{2}$ content was found to increase the degree of crystallinity of BTS2, but led to the crystallization of BTS3 (Takahashi et al., 2008). A further increase in $\mathrm{SiO}_{2}$ content yielded trydimite too. Our findings can be considered to be in agreement with these results. The presence of rutile is justified by the excess titanium resulting from the balance of oxides in the accessory phases.

Synthesis B yielded BTS4 accompanied by fresnoite and rutile. With the composition corresponding to BTS4, also the literature reports tridymite and glass (Köppen \& Dietzel, 1976), implying a non-crystalline fraction enriched in barium and titanium. As the $\mathrm{SiO}_{2}$ content is decreased to approach BTS3 composition, BTS2, BTS4 and silica were detected, whereas fresnoite was found only at higher contents of $\mathrm{BaO}$. The mineral assemblage we obtained is therefore at variance with these results and with the $\mathrm{BaO}-\mathrm{TiO}_{2}-\mathrm{SiO}_{2}$ ternary phase diagram depicted in Fig. 1. Crystallization of fresnoite, hosting more Ba and less silica than BTS4, leads to an excess of silica and titanium, with the latter hosted by rutile. This requires the segregation of some amount of silica. Careful inspection of the powder diffraction pattern did not allow for the identification of any crystalline silica, but the presence of a glass phase enriched in $\mathrm{SiO}_{2}$ accounting for this mismatch cannot be excluded. Although some simulation of crystal habit of BTS4 was found to be compatible with orthorhombic symmetry (see supporting information, Fig. S3 for an example), indexing of the BTS4 powder diffraction pattern turned out to be more complicated than expected. Furthermore, the amount of impurities and the complex texture of the synthesized sample precluded the selection of single crystals. Optimization of the conditions of synthesis in view of structure solution is thus still underway. The main result reported here is the identification of the XRPD pattern of BTS4. Because of its presence in the product of synthesis $A$, these data were essential for the correct indexing of BTS2 and for its structure solution. Several peaks, missing in the work of Köppen \& Dietzel (1976), have been identified (Table S1 of the supporting information). The most striking example is represented by the reflections at 2.15 (2), 1.72 (1) and 1.43 (1) $\AA$. As already mentioned, their relative intensities are likely to be affected by preferred orientation effects; this seems compatible with the tabular crystal habit shown by BTS4 (Fig. S3). For a few reflections, attribution to BTS4 was hindered by overlap with the fresnoite diffraction pattern. The presence of complex twinning in the BTS2 crystals, already observed by Köppen \& Dietzel (1976) and confirmed in this study (see Fig. 2), certainly prevented earlier determination of the crystal structure from singlecrystal diffraction studies. The presence of impurities, such as fresnoite and BTS4, and the coexistence of monoclinic and triclinic domains, make structure solution from powders highly complicated as well. This is likely the reason why previous indexing of the BTS2 powder pattern was incorrect, albeit both Köppen \& Dietzel (1976) and Stassen et al. (1998) realised that BTS2 is monoclinic. It has to be noted, however, that the monoclinic solution previously reported, with $a=$ 11.8831 (7), $b=10.0067$ (5), $c=9.9156(10) \AA$ and $\beta=$ $93.832(6)^{\circ}$ (Stassen et al., 1998), is biased by the presence of fresnoite peaks: see for example the $3.2977 \AA$ reflection, which should be actually indexed as the (201) reflection of fresnoite.

Correctly, the authors admit that the Raman spectrum of BTS2 contains fresnoite bands $\left(\right.$ e.g. $\left.377 \mathrm{~cm}^{-1}\right)$. The BTS2 model described here refers to the average monoclinic structure as obtained from the low-resolution synchrotron data (Set-up 1). The triclinic structure is simply a distortion of the lattice of the monoclinic structure with $\alpha$ and $\gamma$ angles which deviate slightly from $90^{\circ}$. We believe that there is enough experimental evidence (e.g. the similarity between the two structure models, the type of polysynthetic twinning) to consider BTS2 as a case of solid-state transformation twinning with the monoclinic and the triclinic structure models being both low-temperature modifications formed during cooling from the high-temperature form at 923$933 \mathrm{~K}$.

In discussing the results from structure solution, it should be noted that as far as the agreement factors are concerned, for all the refinements the high values of $\chi^{2}$ (see the definition in Larson \& Von Dreele, 2004) are due to the use of soft constraints on the interatomic $\mathrm{Si}-\mathrm{O}$ distances added as variables to the refinement. The structure of BTS2 is composed of layers parallel to the $a c$ plane. Each layer involves isolated four-membered Si-centred tetrahedral rings (Fig. 8a). The presence of unbranched single

Figure 8

Plots of the calculated monoclinic structure model of BTS2 in the $a b$ plane $(a)$ and $a c$ plane $(b)$. 
rings of $\mathrm{Si}_{4} \mathrm{O}_{12}$ was also predicted by Stassen et al. (1998). The corners of unshared tetrahedra are connected to isolated Ticentred square-based pyramids pointing towards the Ba-filled layer (Fig. 8b). The cross-linking of Si-centred tetrahedra and Ti-centred pyramids results in the formation of a two-dimensional channel structure. The apical oxygen of the pyramid (O4 in Table 2) links the polyhedron to the $\mathrm{Ba}$ atoms (two $\mathrm{Ba}-\mathrm{O} 4$ bonds were detected at an average distance of 3.028 (6) $\AA$ in the monoclinic model). The $\mathrm{Ba}$ atoms are coordinated to $12 \mathrm{O}$ atoms at an average distance of 3.085 (3) $\AA$ in the monoclinic model (see Table 2), while Ba1 is coordinated to 12 oxygen atoms at an average distance of 3.080 (3) $\AA$ and $\mathrm{Ba} 2$ is coordinated to $11 \mathrm{O}$ atoms at an average distance of 3.057 (3) $\AA$ in the triclinic model. Comparison with similar metasilicates hosting $\mathrm{Ti}$ or $\mathrm{V}$ in a distorted pyramidal environment shows that the structure of BTS2 has little in common with haradaite $\left(\mathrm{SrVSi}_{2} \mathrm{O}_{7}\right.$; Takeuchi \& Joswig, 1967) and suzukiite $\left(\alpha-\mathrm{BaVSi}_{2} \mathrm{O}_{7}\right.$; Matsubara et al., 1982), whereas it can be described as a distortion of the tetragonal lattice of synthetic $\beta-\mathrm{BaVSi}_{2} \mathrm{O}_{7}$ (Zhu et al., 2003; Liu \& Greedan, 1994) with Ti in place of V.

The unit cell of synthetic $\beta-\mathrm{BaVSi}_{2} \mathrm{O}_{7}$ is $a=7.0535$ (7) and $c=11.467$ (2) $\AA$ in space group $I 4 / m$ and $a=[111]_{\mathrm{BTS}_{2}}$ and $c=$ $[101]_{\mathrm{BTS} 2}$. The mean $\mathrm{Si}-\mathrm{O}$ bond lengths for $\beta-\mathrm{BaVSi}_{2} \mathrm{O}_{7}$ are in the range 1.597 (5)-1.622 (5) $\AA$ (Liu \& Greedan, 1994) and are comparable to the values reported for the two independent tetrahedra of BTS2, although the latter are much more distorted with respect to the regular tetrahedron described for $\beta$ - $\mathrm{BaVSi}_{2} \mathrm{O}_{7}$. The chemical environment (square pyramid) of $\mathrm{V}$ in $\beta-\mathrm{BaVSi}_{2} \mathrm{O}_{7}$ is equivalent to that of Ti in BTS2 with a short axial $\mathrm{V}-\mathrm{O}$ bond of 1.592 (8) $\AA$ and four longer basal distances [1.936 (5) ^; Liu \& Greedan, 1994]. Even the Ba coordination number is identical (12) with an average $\mathrm{Ba}-\mathrm{O}$ bond length of 3.094 (4) $\AA$ in $\beta$ - $\mathrm{BaVSi}_{2} \mathrm{O}_{7}$ and 3.085 (3) $\AA$ in BTS2. Given the evident isomorphism and the comparable atomic radius of $\mathrm{Ti}^{4+}$ and $\mathrm{V}^{4+}$ in fivefold coordination $(0.51$ and $0.53 \AA$, respectively; Shannon, 1976), it is quite surprising that BTS2 possesses monoclinic/triclinic symmetry, whereas $\beta$ $\mathrm{BaVSi}_{2} \mathrm{O}_{7}$ (supposedly a high-temperature form) is tetragonal
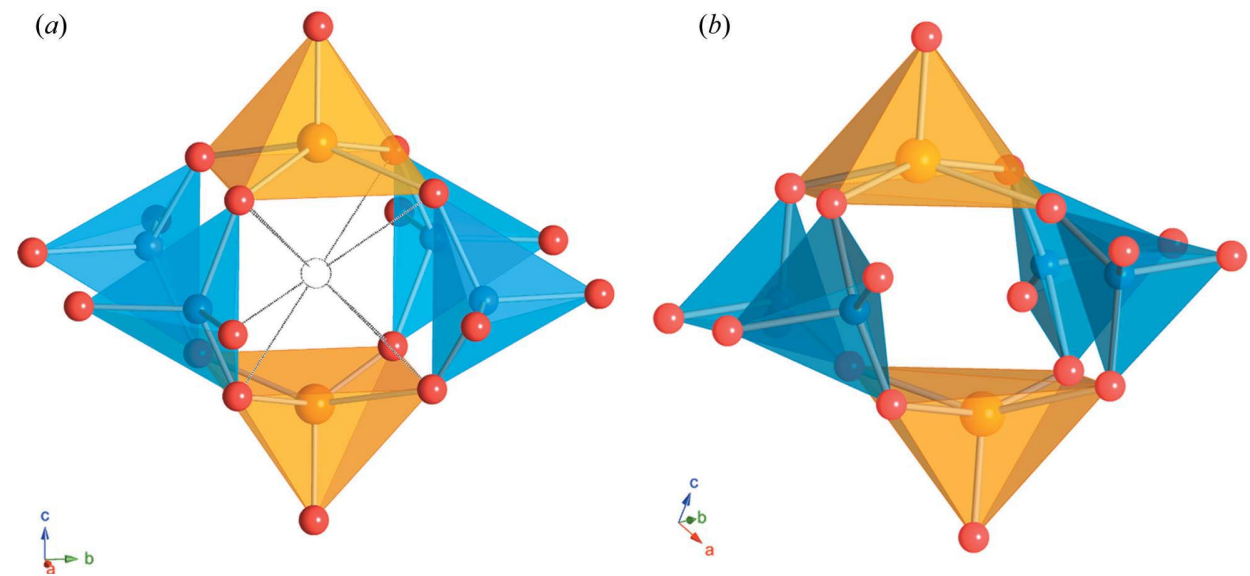

Figure 9

$\mathrm{TiO}_{5}$ structural unit pairs (in yellow) as previously conjectured by Takahashi et al. (2008) (a), and in monoclinic BTS2 (b). and does not show twinning. Planned in-situ X-ray diffraction experiments, aimed at the investigation of the high-temperature phase transitions of BTS2, might shed light on some of these aspects.

Our results have finally disclosed the chemical environment of titanium in BTS2. To date, three possible configurations have been advanced: octahedral as in $\mathrm{BaTiO}_{3}$, fivefold as in fresnoite, or tetrahedral as in $\mathrm{Ba}_{2} \mathrm{TiO}_{4}$ (Takahashi et al., 2012). As already correctly inferred by Stassen et al. (1998), Ti is coordinated to five $\mathrm{O}$ atoms forming a square-based pyramidal polyhedron with one $\mathrm{Ti}=\mathrm{O}$ short bond (with $\mathrm{O} 4$ ) and four 'normal' $\mathrm{Ti}-\mathrm{O}$ bonds (with $\mathrm{O} 1, \mathrm{O} 2, \mathrm{O} 6$ and $\mathrm{O} 7$ ) at a mean distance of $c a 2 \AA$. Hence, the Ti atom is shifted from the centre of the pyramid base towards the apical oxygen. This geometry is similar to the $\mathrm{V}$-centred polyhedra observed in haradaite, cavansite $\left[\mathrm{Ca}(\mathrm{VO}) \mathrm{Si}_{4} \mathrm{O}_{10} \cdot 4 \mathrm{H}_{2} \mathrm{O}\right]$ and pentagonite $\left[\mathrm{Ca}(\mathrm{VO})\left(\mathrm{Si}_{4} \mathrm{O}_{10}\right) \cdot 10 \mathrm{H}_{2} \mathrm{O}\right.$; Liu \& Greedan, 1994]. The Ticentred square pyramids are isolated, although they can be considered as dimerized through four bridging $\mathrm{Si}$ atoms, forming $\left[\mathrm{Si}_{4} \mathrm{Ti}_{2} \mathrm{O}_{18}\right]^{12-}$ clusters (Liu \& Greedan, 1994), as depicted in Fig. 9(b).

The short Ti-O4 bond distance [1.641 (6) $\AA$ in the monoclinic model and $1.612(5) \AA$ in the triclinic model] is not surprising, and in agreement with the Raman data (Stassen $e t$ al., 1998), especially the stretching vibration at $912 \mathrm{~cm}^{-1}$ which is attributed to a pyramidal $\mathrm{TiO}_{5}$ group with one short $\mathrm{Ti}-\mathrm{O}$ distance of $1.65 \AA$ (Blasse \& van den Heuvel, 1974; PaquesLedent, 1976; Gabelica-Robert \& Tarte, 1981). In this configuration, the apical oxygen $\mathrm{O} 4$ is strongly bonded to $\mathrm{Ti}$ (via a double $\mathrm{Ti}=\mathrm{O}$ bond) and virtually not bonded to the other cations of the structure.

Takahashi et al. (2006a) apparently managed to synthesize pure BTS2 showing a clear orange PL at room temperature by UV excitation. In the PL spectra, an excitation peak at $c a$ $321 \mathrm{~nm}$ and a broad emission, peaked at $c a 580 \mathrm{~nm}$, were detected. The PL effect in titanates has long been attributed to the nature and configuration of the Ti units within the structure. Structures containing different Ti coordination polyhedra and with a different level of interconnection were shown to be separated in a plot of wavenumber of excitation peak versus quenching temperature (Takahashi et al., 2006b). Examples of titanosilicates containing isolated pyramidal $\mathrm{TiO}_{5}$ units with a short $\mathrm{Ti}-\mathrm{O}$ distance and sharing basal $\mathrm{O}$ atoms with $\mathrm{SiO}_{4}$ tetrahedra, similar to BTS2, are scarce. The most remarkable are fresnoite and the isostructural $\mathrm{Li}_{2} \mathrm{TiSiO}_{5}$ and $\mathrm{Na}_{2} \mathrm{TiSiO}_{5}$. All of them show PL properties at room temperature, but the mechanism of PL is still debated. For fresnoite, fresnoite glasses and glass-ceramics the PL effect has been attributed to the $\mathrm{CT}$ transition localized in the $\mathrm{TiO}_{5}$ 
pyramid with a subsequent ${ }^{3} T_{1} \rightarrow{ }^{1} A_{1}$ transition to the ground state (Takahashi et al., 2012). A similar mechanism was also invoked previously for $\mathrm{Li}_{2} \mathrm{TiSiO}_{5}$ (Bouma \& Blasse, 1995). These interpretations stem from the hypothesis that PL at room temperature in similar structures originates in the energy-confinement of excitons in the isolated $\mathrm{Ti}-\mathrm{O}$ polyhedral units because of the absence of $d$-orbital overlap. However, quantum-mechanical calculations indicated that differently charged clusters, creating a polarization, and some structural disorder, leading to the presence of localized levels able to trap electrons and holes and favouring the radiative return to the ground state, are the conditions for PL emission in the disordered $\mathrm{Li}_{2} \mathrm{TiSiO}_{5}$ system (Orhan et al., 2004). On this basis, the authors considered the coexistence of the $\mathrm{SiO}_{4}-$ $\mathrm{TiO}_{5}$ clusters, and not the presence of isolated square $\mathrm{TiO}_{5}$ pyramids, as the key structural motifs leading to PL in crystalline $\mathrm{Li}_{2} \mathrm{TiSiO}_{5}$.

It is thus clear that knowledge of the structure alone does not allow the correct interpretation of the PL effect. This is especially true for BTS2, being rather unique amongst silicotitanates. Although the orange-red component of the PL spectrum has been recognized to be somehow related to the presence of $\mathrm{Ti}$ in fivefold coordination in titanate glasses (Macke, 1976), and recently also correlated with theoretical modelling of band structure (Orhan et al., 2004), BTS2 is the only crystalline ordered phase containing isolated $\mathrm{TiO}_{5}$ units that shows a dominant orange PL. Furthermore, its wavenumber of excitation peak/quenching temperature ratio is well above that expected (Takahashi et al., 2006b). Such aspects found justification in a model for PL based on the assumption that BTS2 shows structural similarities with tetragonal $\beta$ $\mathrm{BaVSi}_{2} \mathrm{O}_{7}$ (Takahashi et al., 2006b). According to this model, PL in BTS2 can be attributed to both the charge-transfer transition of $\mathrm{O}-\mathrm{Ti}^{3+}$ involving the short $\mathrm{Ti}-\mathrm{O} 4$ bond in the pyramidal $\mathrm{TiO}_{5}$ unit and oxygen defects in the same pyramidal unit. PL originates in the charge-transfer CT transition from the $2 p$ orbitals of the surrounding oxygen ion to the empty outer $3 d$ orbital of $\mathrm{Ti}^{4+}$ in the titanium-oxygen polyhedral unit, i.e. $\mathrm{O}^{2-}-\mathrm{Ti}^{4+} \rightarrow \mathrm{O}^{-}-\mathrm{Ti}^{3+}$, and the subsequent transition of ${ }^{3} T_{1} \rightarrow{ }^{1} A_{1}$, which was excited by the CT transition, through Stokes shift (Takahashi et al., 2006a, 2008; Iwasaki et al., 2009).

The presence of oxygen defects in the $\mathrm{Ti}-\mathrm{O}$ unit was also supported by the observation that the band edge in the diffuse reflection spectrum was obscure around $350 \mathrm{~nm}$ (De Haart et al., 1985). The structure solution provided by our study ultimately demonstrates the presence of pyramidal fivefold coordinated $\mathrm{Ti}$ atoms and substantially confirms this model. If we consider negative charge undersaturation of a crystallographic site as indicative, bond-valence calculations suggest that possible sites hosting the oxygen vacancy in the crystal lattice are $\mathrm{O} 1$ and $\mathrm{O} 7$ in the monoclinic structure and the corresponding $\mathrm{O} 1$ and $\mathrm{O} 13$ in the triclinic structure (see Table 3 ). The refinement of O1 site occupancy of the monoclinic structure to a value less than 1, although it should be considered cautiously in terms of its absolute value (see the considerations expressed in the previous section), may however further support this view. It is worth noting that, in addition to oxygen vacancies in $\mathrm{TiO}_{5}$ units, the presence of intrinsic defects in octahedral $\mathrm{TiO}_{6}$ units, was also postulated for BTS2 (Takahashi et al., 2006b, 2008). In fact, the $\mathrm{TiO}_{5}$ pyramid was regarded as a $\mathrm{TiO}_{6}$ polyhedron deprived of one apical oxygen. This vacancy was considered structurally present in BTS2 because of the presence of two $\mathrm{TiO}_{5}$ pyramids facing opposite directions, suggesting that one oxygen in the middle of two $\mathrm{TiO}_{6}$ units (indicated by the grey dotted circle in Fig. 9a) was lacking. This should correspond to the oxygen shared by two octahedra in a perovskite-like arrangement. It should be pointed out, however, that such a condition no longer holds when the symmetry lowers from tetragonal (as in $\beta$ - $\mathrm{BaVSi}_{2} \mathrm{O}_{7}$, and as supposed by the authors) to monoclinic/ triclinic (as in BTS2). In this case, as depicted in Fig. 9(b), the two bases of the $\mathrm{TiO}_{5}$ pyramids are not exactly superimposed and no unique crystallographic position, corresponding to an oxygen vacancy common to two $\mathrm{TiO}_{6}$ units, can be identified (except at the price of a strong octahedral distortion). In this respect, a comparison between the two structures by $a b$ initio quantum-mechanical calculations might shed some light on this aspect. This approach has been considered beyond the scope of the present paper and subordinated to the investigations of the Ti environment with the aid of X-ray absorption spectroscopy that are underway.

\section{Conclusions}

In this work we have synthesized BTS2 and BTS4 but the attainment of pure compounds was not possible. This fact is strictly related to the stability fields of the phases, as shown by the $\mathrm{BaO}-\mathrm{TiO}_{2}-\mathrm{SiO}_{2}$ ternary phase diagram. Extensive polysynthetic twinning, affecting BTS2, prevented structure solution from single-crystal diffraction. Structure solution was attempted from powder diffraction data. The structure complexity of BTS2 is due to the presence of monoclinic and triclinic domains within the same crystals. The monoclinic phase has the space group $P 2_{1} / n$ and unit cell $a=7.9836$ (3), $b=10.0084$ (4), $c=7.4795$ (3) $\AA$ and $\beta=100.321$ (3) $)^{\circ}$, whereas the triclinic phase has the space group $P \overline{1}$ and unit cell $a=$

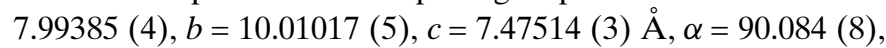
$\beta=100.368$ (8) and $\gamma=89.937$ (9) $)^{\circ}$. Bond-valence calculations were used to validate the crystal structures. Peculiar to them is the presence of isolated Ti-centred square pyramids, with one short $\mathrm{Ti}-\mathrm{O}$ distance involving the apical oxygen. This structural unit, previously inferred from PL and Raman investigations, has now been confirmed. BTS2 crystal structure can be related to that of $\beta$ - $\mathrm{BaVSi}_{2} \mathrm{O}_{7}$ by a distortion of its tetragonal lattice. Charge understauration and occupancy of one crystallographic site less than unity in the $\mathrm{TiO}_{5}$ pyramids was also detected for the monoclinic structure. The proposed solution is, at least in part, in agreement with existing theories on the explanation of the PL orange colour in BTS2, requiring both charge transfer involving the short $\mathrm{Ti}-\mathrm{O}$ bond and oxygen defects in the pyramidal units. The effect of the distortion of the $\beta$ - $\mathrm{BaVSi}_{2} \mathrm{O}_{7}$ tetragonal lattice was however not considered in these theories. 
Future investigations include the study of the local structure at the Ti absorption edge by X-ray absorption spectroscopy, and the study of the reversible phase transition between the two polymorphs of BTS2 at about $923-933 \mathrm{~K}$ by means of insitu XRPD.

\section{Acknowledgements}

We kindly acknowledge Professor G. Cruciani for collecting the powder spectrum of BTS2 at ID31 (ESRF, Grenoble, France). Thanks are due to the technical staff of the C.I.G.S. Laboratory (The University of Modena and R.E., Modena, Italy) with a special mention to M. Tonelli, C. Rossi and M. Zapparoli for their help during the SEM and TEM experimental sessions. Thanks to M. Bortolotti for his help with the laboratory analyses. This research was partially supported by the project No. LO1219 under the Ministry of Education, Youth and Sports National sustainability programme I of Czech Republic. Experiments at the Elettra synchrotron facility (Basovizza, TS, Italy) (Proposal No. 20130032) were granted as an Italian funded user.

\section{References}

Altomare, A., Camalli, M., Cuocci, C., Giacovazzo, C., Moliterni, A. \& Rizzi, R. (2009). J. Appl. Cryst. 42, 1197-1202.

Altomare, A., Cuocci, C., Giacovazzo, C., Moliterni, A., Rizzi, R., Corriero, N. \& Falcicchio, A. (2013). J. Appl. Cryst. 46, 1231-1235.

Blasse, G. \& van Den Heuvel, G. P. M. (1974). J. Solid State Chem. 10, 206-210.

Bouma, B. \& Blasse, G. (1995). J. Phys. Chem. Solids, 56, 261-265.

Catti, M., Gazzoni, G. \& Ivaldi, G. (1983). Acta Cryst. C39, 29-34.

Deer, W. A., Howie, R. A. \& Zussman, J. (2013). An Introduction to the Rock Forming Minerals. Bath: Geological Society of London.

De Haart, L. J. G., De Vries, A. J. \& Blasse, G. (1985). J. Solid State Chem. 59, 291-300.

Donnay, G. \& Donnay, J. D. H. (1974). Can. Mineral. 12, 422-425.

Gabelica-Robert, M. \& Tarte, P. (1981). Phys. Chem. Miner. 7, 26-30.
Gaft, M., Nagli, L., Waychunas, G. \& Weiss, D. (2004). Phys. Chem. Miner. 31, 365-373.

Hammersley, A. P. (1993). FIT2D Reference Manual. ESRF Internal Report, Exp/AH/92-02. European Synchrotron Radiation Facility, Grenoble, France.

Iwasaki, K., Takahashi, Y., Masai, H. \& Fujiwara, T. (2009). Opt. Express, 17, 18054-18062.

Köppen, N. \& Dietzel, A. (1976). Glastech. Ber. 49, 199-206.

Larson, A. C. \& Von Dreele, R. B. (2004). GSAS. Report LAUR. Los Alamos National Laboratory, New Mexico, USA.

Laugier, J. \& Bochu, B. (2014). LMGP software, http://pcb4122.univlemans.Fr/du-sdpd/nexus/CCP14/web/tutorial/lmgp/index.htm\# chekcell.

Liu, G. \& Greedan, J. E. (1994). J. Solid State Chem. 108, 267274.

Macke, A. J. H. (1976). J. Solid State Chem. 18, 337-346.

Matsubara, S., Kato, S. \& Yui, S. (1982). Jpn Miner. J. 11, 15-20.

Orhan, E., Albarici, V. C., Escote, M. T., Machado, M. A. C., Pizani, P. S., Leite, E. R., Sambrano, J. R., Varela, J. A. \& Longo, E. (2004). Chem. Phys. Lett. 398, 330-335.

Paques-Ledent, M. T. (1976). Spectrochim. Acta A, 32, 1339-1344.

Parsons, S. (2003). Acta Cryst. D59, 1995-2003.

Shannon, R. D. (1976). Acta Cryst. A32, 751-767.

Stassen, S., Tarte, P. \& Rulmont, A. (1998). Spectrochim. Acta A Mol. Biomol. Spectrosc. 54, 1423-1431.

Takahashi, Y., Iwasaki, K. \& Fujiwara, T. (2012). Phys. Status Solidi (C), 9, 2336-2339.

Takahashi, Y., Kitamura, K., Iyi, N. \& Inoue, S. (2006a). J. Ceram. Soc. Jpn, 114, 313-317.

Takahashi, Y., Kitamura, K., Iyi, N. \& Inoue, S. (2006b). Appl. Phys. Lett. 88, 151903-1-151903-3.

Takahashi, Y., Konishi, T., Soga, K. \& Fujiwara, T. (2008). J. Ceram. Soc. Jpn, 116, 1104-1107.

Takeuchi, Y. \& Joswig, W. (1967). Miner. J. 5, 98-123.

Tarte, P. (1990). Solid State Ionics, 42, 177-196.

Toby, B. H. (2001). J. Appl. Cryst. 34, 210-213.

Werner, P.-E., Eriksson, L. \& Westdahl, M. (1985). J. Appl. Cryst. 18, 367-370.

Žák, L. (1973). Neues Jahrb. Miner. Monatsh. 4, 183-189.

Zhu, M., Wang, B., Liu, P., Yan, H. \& Ding, Z. (2003). Opt. Mater. 23, 323-326. 